\title{
Relationship between the sexual and the vegetative organs in a Polygonatum humile (Liliaceae) population in a temperate forest gap
}

Byeong-Mee Min

\begin{abstract}
Background: The aim of this study was to clarify the relationship between the sexual reproduction and the resource allocation in a natural Polygonatum humile population grown in a temperate mixed forest gap. For this aim, the plant size, the node which flower was formed, the fruiting rate, and the dry weight of each organ were monitored from June 2014 to August 2015.

Results: Firstly, in 3-13-leaf plants, plants with leaves $\leq 8$ did not have flowers and in plants with over 9 leaves the flowering rate increased with the number of leaves. Among plants with the same number of leaves, the total leaf area and dry weight of flowering plants were larger than those of non-flowering plants. The minimum leaf area and dry weight of flowering plants were $100 \mathrm{~cm}^{2}$ and $200 \mathrm{mg}$, respectively. Secondary, the flowers were formed at the 3rd 8th nodes, and the flowering rate was highest at the 5 th node. Thirdly, cumulative values of leaf properties from the last leaf (the top leaf on a stem) to the same leaf rank were greater in a plant with a reproductive organ than in a plant without a reproductive organ. Fourthly, fruit set was $6.1 \%$ and faithful fruit was $2.6 \%$ of total flowers. Biomasses of new rhizomes produced per milligram dry weight of leaf were $0.397 \pm 190 \mathrm{mg}$ in plants that set fruit and $0.520 \pm 0.263 \mathrm{mg}$ in plants that did not, and the difference between the 2 plant groups was significant at the $0.1 \%$ level.
\end{abstract}

Conclusions: $P$. humile showed that the 1 st flower formed on the 3 rd node from the shoot's base. And $P$. humile showed the minimum plant size needed in fruiting, and fruiting restricted the growth of new rhizomes. However, the fruiting rate was very low. Thus, it was thought that the low fruiting rate caused more energy to invest in the rhizomes, leading to a longer rhizome. A longer rhizome was thought to be more advantageous than a short one to avoid the shading.

Keywords: Flowering rate, Fruiting, Leaf area, Leaf dry weight, Polygonatum humile, Rhizome

\section{Background}

In temperate deciduous forests, understory herbaceous plants grow under insufficient irradiance after canopy closure (Emborg 1998, Augusto et al. 2003). These plants use diverse strategies to adapt to the low-light environment. Spring ephemerals complete life cycles before canopy closure, and shade-tolerant plants slowly grow (Schemske et al. 1978, Houle 2002, Legner et al.

Correspondence: bmeemin@hanmail.net

Department of Science Education, Dankook University, Yongin 16890, South Korea
2013). In any case, photosynthetic substances produced during the growing season are limited, and understory plants use the pertinent energy strategy to ensure their survival and reproduction. In particular, a young perennial herbaceous plant invests energy in growth or survival rather than in reproduction until its size is to a certain extent (Silvertown 1982, Hartnett 1990). These plant species reproduce asexually and sexually. Asexual reproduction is closely related to growth, and generally, reproductive potential is evaluated by the sexual one. Reproductive potential of perennial herbaceous species 
depends on plant size rather than on its age (Klinkhamer et al. 1992). When clonal plants reach the reproductive stage, sexual reproduction and vegetative propagation may compete for resources in the plant (Cook 1983). In perennial herbaceous plants, resource allocation to asexual and sexual reproduction is an indicator of adaptive plasticity and a strategy for survival, and this topic has been addressed many times in population ecology (Jerling 1988, de Kroon and Schieving 1991). Moreover, information on reproduction strategies is essential to predict for population dynamics in the future (Silvertown 1982). In other words, in clonal perennial herbaceous plants, energy budget strategies for asexual and sexual reproduction determine the entire life cycle, and the plant's response resulting from these strategies is the basis for interpreting environmental adaptation or genetic output (Stephenson 1981). Microenvironmental adaptation to insufficient sunlight is transiently reflected by morphological and physiological diversity. However, the energy budget in a plant cannot be precisely divided into that for asexual and sexual reproduction because of methodological and physiological difficulties (Klinkhamer et al. 1990). Putting aside respiration during seed production, total net production by a plant does not remain at its disposal, since photosynthetates are lost because of organ death, herbivore predation, and physical damage. Thus, to estimate the energy used for sexual reproduction, an indirect method has been used: sexual organs are removed and weighed, and biomasses are compared for flowering and non-flowering plants (Klinkhamer et al. 1990, Ehrlén and van Groendael 2001). This method has been tested in diverse settings by many researchers (Samon and Werk 1986, Reekie and Bazzaz 1987, Verburg et al. 1996). They used the term "reproductive efforts" with respect to the plant's reproductive investment. Reproductive efforts are the rate of the overall resources (biomass or nutrients) used for reproductive organs or seeds.

Polygonatum humile (Liliaceae) is generally distributed in grasslands or at the periphery of a shrub in Korea (Choung 1991, Jang 2002) or in grasslands and sand dunes in Japan (Hasegawa and Kudo 2005). Thus, this species needs full sunlight. And P. humile is a clonal perennial herb, which reproduces asexually by rhizomes and sexually by seeds (Choung 1991, Hasegawa and Kudo 2005). Unlike other species of genus Polygonatum, the shoots of $P$. humile are erect and its rhizomes are long (Jang 2002, Hasegawa and Kudo 2005). The total length of the rhizome which grows for about 3.3 years and is connected in 1 line is $47.6 \pm 25.6 \mathrm{~cm}$ a shoot, and rhizomes grow at a rate of $15.5 \pm 4.4 \mathrm{~cm}$ a year (Hasegawa and Kudo 2005). Each plant has 2 rhizomes (Choung 1991, Jang et al. 1998) or 1 4 rhizomes (Jang 2002). The flower germinates from the axilla of the leaf (node). The number of flowers is 19.0 (Jang et al. 1998) or $2.7 \pm 1.1$ (Hasegawa and Kudo 2005) per stem and 2 6 (Jang et al. 1998) or 1 (Jang 2002) or 1 2 (Lee 2003) per node. The reported number of seeds per fruit is $6.1 \pm 2.71$ (Hasegawa and Kudo 2005) or many (Jang 2002). Thus, the number of flowers produced by $P$. humile varied according to the reports. Besides the studies mentioned above, there are few ecological studies on P. humile. Moreover, there are much fewer pharmaceutical and agricultural studies for P. humile than for other Polygonatum species (Seo et al. 2011).

The aim of this study was to clarify the relationship between the sexual reproduction and the resource allocation in a natural $P$. humile population grown in a temperate mixed forest gap. For this aim, the plant size, the node which flower was formed, the fruiting rate, and the dry weight of each organ were monitored from June 2014 to August 2015. The properties of plant sizes were the leaf area, the dry weight of leaf, root and rhizome, and the length of stem and rhizome.

\section{Methods}

The study area was located at Yeongheung-ri, Yeongwaleup, Yeongwal-gun, Gangwon province ( $37^{\circ} 11^{\prime} 35.7^{\prime \prime}$ $\left.\mathrm{N}, 128^{\circ} 28^{\prime} 04.0^{\prime \prime} \mathrm{E}\right)$. The study site was $385 \mathrm{~m}$ a.s.l. (slope, $5^{\circ}$; direction, $175^{\circ}$ ). Annual mean air temperature and precipitation in an average year were $10.8^{\circ} \mathrm{C}$ and $1224.1 \mathrm{~mm}$, respectively, and those in 2015 were $12.5^{\circ} \mathrm{C}$ and $676 \mathrm{~mm}$, respectively, on Yeongwal Meteorological Station. $P$. humile grew in a gap created to move a grave to another place (radius, $10 \mathrm{~m}$ ) and was momentarily shaded by trees in the south. P. humile's patch was about a $5 \mathrm{~m} \times 6 \mathrm{~m}$ circle. Except for $P$. humile, the herb layer was $5 \%$ in coverage and composed of Aster scaber, Carex lanceolata, Festuca ovina, and Zoysia japonica. The surrounding forest had 4 layers of vegetation. The tree layer was composed of Pinus densiflora, Quercus mongolica, and Quercus dentata and had 90\% coverage. There were P. densiflora, Quercus serrata, Prunus sargentii, and Euonymus sieboldiana and $40 \%$ coverage in the subtree layer. There were Exochorda serratifolia, Pourthiaea villosa, and Rhododendron mucronulatum in the shrub layer and C. lanceolata, Leibnitzia anandria, and A. scaber in the herb one. The coverage was $10 \%$ in the former and $1 \%$ in the latter. The litter layer was $10-\mathrm{cm}$ deep and a layer of soil was 10-cm deep. However, the soil of the study area where the $P$. humile population was distributed had been disturbed by the work in relocating the grave but had settled by the time of the study. A field survey was carried out for 2 purposes. One was to check the changes in the sexual organ. A quadrat of $2 \times 2 \mathrm{~m}$ was chosen on April 25, 2015. Each flowering plant of $P$. humile was numbered by using a plastic rod, 
and the phenological stages of the sexual organ were checked every week till June 27, 2015. The phenological stages were based on Hasegawa and Kudo (2005). At the end of August 2015, all numbered plants were dug out. The other was to conform the difference between flowering plants and non-flowering ones, so that all plants of $P$. humile were divided into 2 groups and the properties of the plant organ analyzed. In the lab, the plants were divided into the root and shoot systems. The roots were separated according to the age of the rhizome, and the rhizomes were numbered $R_{0}$ (this year's rhizome), $R_{1}$ (the last year's rhizome), and $R_{2}$ (2-years-ago rhizome). The leaf ranks on a stem were numbered from the lowest (the leaf closest to the soil surface) or the 1st leaf on a stem $\left(\mathrm{L}_{1}\right)$ to the highest (the last leaf on a stem). The position of the leaf was coincided with a node, so that the leaf rank on a stem was the same as the node one. And flowers germinated in the axilla of leaf (node). Thus, $\mathrm{L}_{1}$ was the same as the 1 st node. The number of leaves on a stem was from 3 to 13. However, 13-leaf plants (13-L) were not sufficiently sampled and were excluded from the analysis. Length, width, and/or area of the rhizomes, leaves, and stems were measured, followed by oven-drying at $85{ }^{\circ} \mathrm{C}$ for $48 \mathrm{~h}$ and weighing on a Hansung Analytical \& Precision Balance, Model MARK M (1-mg unit), and Model YMJ-C Digital Leaf Area Meter $\left(0.0001-\mathrm{cm}^{2}\right.$ unit). The total leaf area, total leaf dry weight, and specific leaf area of a plant were divided into the 10 classes. That was, the total leaf area, the total leaf dry weight, and the specific leaf area were divided by $20 \mathrm{~cm}^{2}$ (range of 59-260 $\mathrm{cm}^{2}$ ), $100 \mathrm{mg}$ (range of 99$1252 \mathrm{mg}$ ), and $30 \mathrm{~cm}^{2} \mathrm{~g}^{-1}$ (range of 203-511 $\mathrm{cm}^{2} \mathrm{~g}^{-1}$ ), respectively. The cumulative values of leaf properties of a stem were calculated for the following reasons and methods. In this study, I made 2 assumptions for the resource allocation during the main growth season. Firstly, the photosynthetic substance produced in the leaf moved from the last leaf to the new rhizome $\left(R_{0}\right)$. Secondary, the resource provided to the reproductive organ (flower or fruit) was synthesized in posterior leaves (the last leaf rank direction) rather than in the anterior ones ( $\mathrm{L}_{1}$ direction), based on the reproductive organ. Thus, it was thought that leaves in the posterior nodes based on the reproductive organ had a profound effect on seed production. Cumulative values of leaf properties were summed for the flowering plants from the last leaf to the closest leaf rank having a reproductive organ $\left(\mathrm{L}_{\mathrm{R}}\right)$. Types of $\mathrm{L}_{\mathrm{R}}$ were $\mathrm{L}_{3}, \mathrm{~L}_{4}, \mathrm{~L}_{5}, \mathrm{~L}_{6}, \mathrm{~L}_{7}$, and $\mathrm{L}_{8}$, but $\mathrm{L}_{3}$ was excluded in the analysis. To compare, the cumulative values of leaf properties for the non-flowering plants were summed from the last leaf to the leaf which its rank was the same as $L_{R}$ but did not have a reproductive organ. This time, the specific leaf area (SLA) was not cumulative but mean values. Significance of the differences was verified by Student's $t$ test, and correlation coefficients (CCs) between the 2 factors were calculated by using Pearson's equation $(y=a x+b)$.

\section{Results and discussion}

Relationship between the sexual organ and the plant size The flower bud of $P$. humile appeared at the same time as the leafing on April 20, 2015, and the last petal was attached until May 30, 2015. And the fruit was 1st observed on May 21, 2015, and remained on the node at the end time of the field survey (September 10, 2015). Two thirds of $P$. humile's shoots have sprouted, and small flower buds at the nodes were observed by April 25, 2015. The 1st fruit was firstly observed on May 20, 2015, and all corollas fell down by May 27, 2015 (Table 1). Thus, corollas attached at the nodes were observed during 37 days in this $P$. humile population. After June 2, 2015, the peduncle (after flower fall) or fruit was observed. However, because the 3 stages (flower budding, flowering, and flower withering) could not be easily distinguished, it was determined whether a white corolla was attached at the node or not. In Japan, $P$. humile's shoots sprouted in mid-May, and it flowers from June 5 to June 22 at high latitude $\left(42^{\circ} 39^{\prime} \mathrm{N}\right)$ (Hasegawa and Kudo 2005). Thus, the flowering time of $P$. humile is very diverse on the habitat. The fruit set was $6.1 \%$ of the total flowers, and $2.6 \%$ of those were over $110 \mathrm{mg}$ (the fruit where the diameter was over $8 \mathrm{~mm}$, faithful fruit) and the remainder (the fruit where the diameter was about below $5 \mathrm{~mm}, 3.5 \%$ ) below $64 \mathrm{mg}$ (Table 1). The criterion of whether the fruit was faithful followed Lee (1996). By Lee (1996), P. humile's fruit is 8$9 \mathrm{~mm}$ in diameter. However, the fruit set was 49-61\% (Hasegawa and Kudo 2005) or 75.9\% (Jang et al. 1998). Thus, the fruit set of $P$. humile was much lower in this study than in the other 2 studies, likely because the plants

Table 1 Fruit set in the P. humile population 2014 and 2015 (size of fruit)

\begin{tabular}{|c|c|c|c|c|}
\hline \multirow[t]{2}{*}{ Date } & \multirow{2}{*}{$\begin{array}{l}\text { No. of } \\
\text { flower }\end{array}$} & \multicolumn{3}{|l|}{ Size of fruit (rate) } \\
\hline & & Over 110 mg (faithful) & Under 64 mg (unfaithful) & Total \\
\hline Aug. 22, 2014 & 148 & $5(3.5 \%)$ & $7(4.7 \%)$ & $12(8.1 \%)$ \\
\hline Aug. 26, 2015 & 196 & $4(2.5 \%)$ & $5(2.6 \%)$ & $9(4.1 \%)$ \\
\hline Total (rate) & 344 & $9(2.6 \%)$ & $12(3.5 \%)$ & $21(6.1 \%)$ \\
\hline
\end{tabular}


examined in this study grew in a forest gap, where sunlight was insufficient, whereas plants examined in the other 2 studies grew in full sunlight. Although sexual reproduction could be limited, the study site was over $5 \mathrm{~cm}$ in the litter layer and soil water was not in shortage by shading. Thus, because of insufficient sunlight, $P$. humile growing in a forest gap might prefer asexual reproduction rather than the sexual one. The number and the largest length of rhizome per shoot were 1 3 and 25.5 $\mathrm{cm}$, respectively, as the previous report.

The minimum number of leaves needed for flowering (at least 1 flower per stem) was 9 (Fig. 1). The flowering rate increased with the number of leaves, and that of 13leaf plants was $100 \%$. There were no flowering plants with a total leaf area per plant below $100 \mathrm{~cm}^{2}$. The flowering rate increased with leaf area, and plants with leaf area over $240 \mathrm{~cm}^{2}$ had $100 \%$ flowering rate. The flowering rate increased with leaf dry weight and was $5 \%$ at $200 \mathrm{mg}$ and $100 \%$ at $>800 \mathrm{mg}$. However, the flowering rate showed 2 peaks with an increase of SLA and was almost not affected by SLA values. As a result, the flowering rate of $P$. humile increased with leaf size. For the same number of leaves, each organ of the flowering plants was larger than that of the non-flowering plants, but SLA was not. Moreover, of the 11 properties, the differences between the 2 groups were significant at the $0.1 \sim 5 \%$ level in 6 properties in 9-leaf plants, in 10 in 10leaf plants, and in 6 in 11-leaf plants (Fig. 2). Leaf area and dry weight significantly differed between the 2 groups at the $0.1 \sim 5 \%$ level regardless of the number of leaves. However, SLA and rhizome size significantly differed between the 2 groups at the $0.1 \sim 5 \%$ level for 10 leaf plants only. The differences in stem length and dry weight between the 2 groups were significant at the $0.1 \sim 1 \%$ level in the 9- and 10-leaf plants. According to these results, the $P$. humile population showed the following properties. Generally, a minimum plant size is required before sexual reproduction occurs (Hirose and Kachi 1982, Schmid and Weiner 1993). Plant flowering in the field was positively correlated with shoot size (Verburg et al. 1996). However, the relationship between plant size and vegetative reproductive effort has received little attention and data are scarce, and methodological and physiological difficulties remained (as mentioned above). First, $P$. humile required a minimum number of leaves for sexual reproduction. And the number of leaves might be an indicator of plant size. However, the number of leaves was not an appropriate indicator because the flowering rate was not $100 \%$ even in 12-leaf plants which almost reached maximum size. Moreover, if the number of leaves and flower buds had been determined before the shoot sprouting, the flowering plants might have already invested more energy from the rhizome into shoot growth than the non-flowering plants regardless of the fruit set. In other words, plants that formed
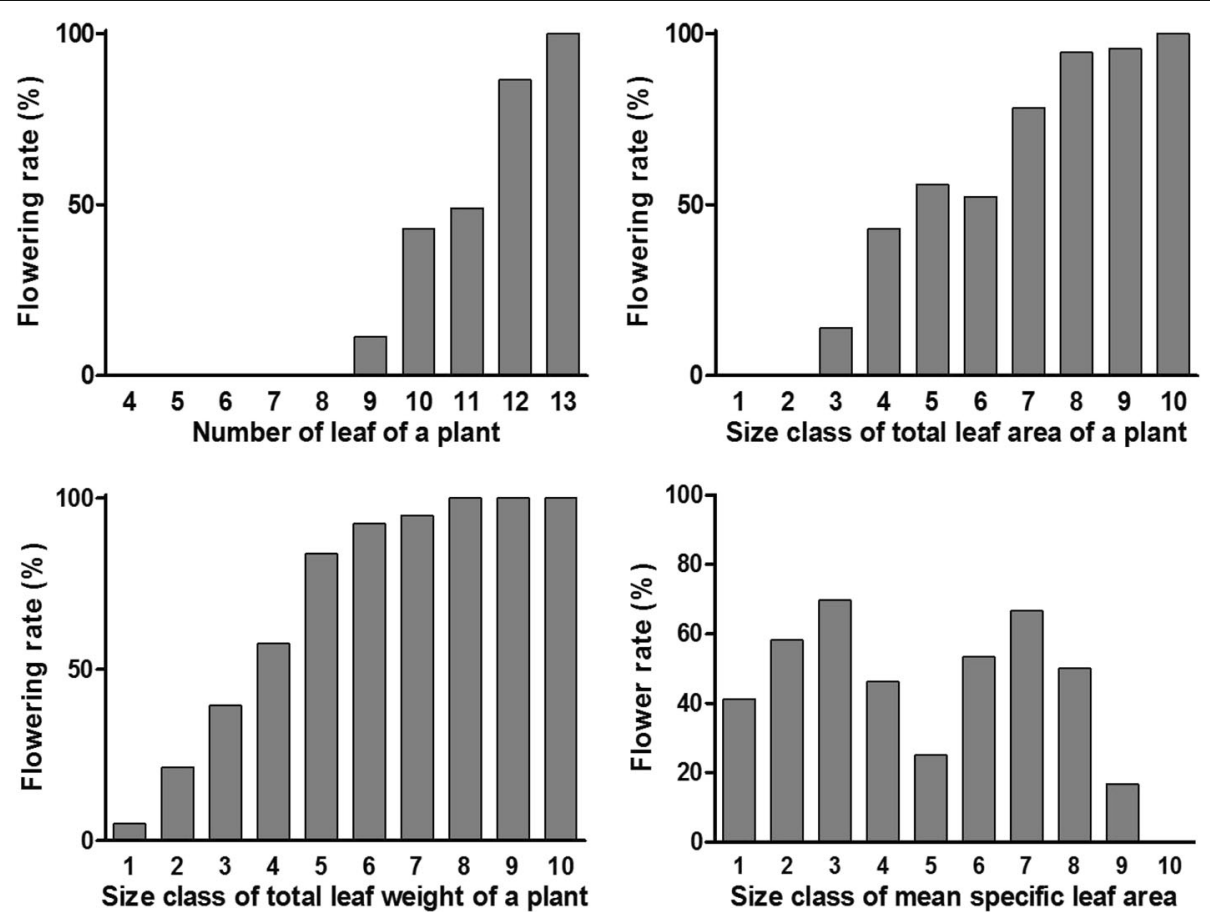

Fig. 1 Flowering rate along the number of leaves $(n=412)$ and the size classes of the total leaf area, the total leaf dry weight, and the mean SLA $(n=246)$ of a plant 

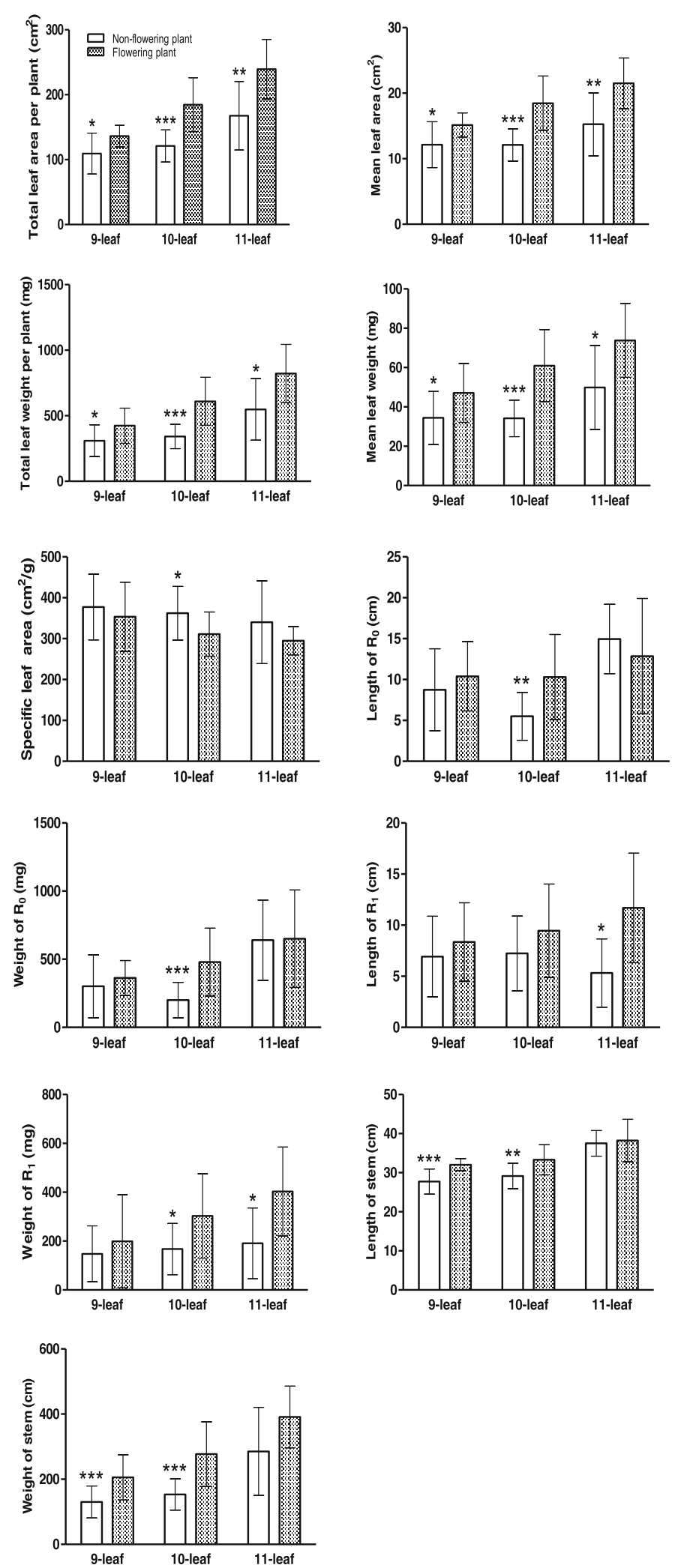

Fig. 2 Comparison of organ sizes between the flowering and the non-flowering plants which had the same number of leaves on June $28,2014$. $*^{*}, *^{*}$, and ${ }^{* * *}$ indicate the significant level at 5,1 , and $0.1 \%$, respectively 
flower buds probably invested energy into other organs rather than only in the increase in the number of leaves. Second, stem length in plants that had $\geq 11$ leaves was maximal, whether the plants flowered or not. Unlikely other species in genus Polygonum, $P$. humile shoot erects. Third, the flowering rate increased with the total leaf area but was $100 \%$ at the largest class only. Thus, stem length and total leaf area were not good indicators of flowering plants. Fourth, the increase of total leaf dry weight was proportioned to the flowering rate. Thus, total leaf dry weight was thought to be the most proper indicator of the relationship between the plant size and flowering.

\section{Leaf ranks (or nodes) with flower}

Each leaf rank (node) had a flower or not. And the flower was from the 3rd node (or $\mathrm{L}_{3}$ ) to the 6th node (or $\mathrm{L}_{6}$ ) in 9-leaf plants and from $\mathrm{L}_{3}$ to $\mathrm{L}_{8}$ in 10 12leaf plants. Thus, there was no flower at 2 nodes from the bottom and at 2 4 nodes from the top. The flowering rate was highest at the $\mathrm{L}_{5}$ in 9 12-leaf plants and decreased toward the bottom (in the direction of the $\mathrm{L}_{1}$ ) and to the top (in the direction of the last leaf) (Fig. 3). The resource provided to reproductive organ (flower or fruit) was synthesized in posterior leaves (the last leaf direction) rather than in the anterior ones (the $\mathrm{L}_{1}$ direction), based on a reproductive organ. Cumulative values of leaf properties were summed for the flowering plants from the last leaf to the closest leaf rank having a reproductive organ $\left(L_{R}\right)$. To compare, cumulative values of leaf properties for the non-flowering plants were summed from the last leaf to the leaf where its rank was the same as $L_{R}$ but did not have a reproductive organ. At each leaf rank, the cumulative values of leaf area and leaf dry weight were larger in the flowering plants ( $\mathrm{L}_{\mathrm{R}}$ plants) than in the nonflowering plants (non- $\mathrm{L}_{\mathrm{R}}$ plants) (Fig. 4), and the differences between the 2 groups were almost significant at the $5 \%$ level. In particular, the cumulative values of leaf properties from the $\mathrm{L}_{12}$ to the $\mathrm{L}_{8}$ in 12-L were larger in plants with $L_{R}$ at the $L_{8}$ than in plants without a reproductive organ to the $\mathrm{L}_{8}$. On the fact that the flowers were mainly in the middle of the stem, it was thought that flowers secured 2 4 leaves supplying photosynthetic substances for fruit setting, whereas the 2 or 3 leaves at the bottom might have provided energy to the root system (rhizome and root) regardless of the fruit set. However, if photosynthetic substances are transported both up and down, sexual reproduction and rhizome growth might compete for resources. Generally, in clonal plants, sexual reproduction and vegetative propagation may compete for resources within the plant (Cook 1983), and P. humile is a clonal plant. Energy used for flower bud germination can be
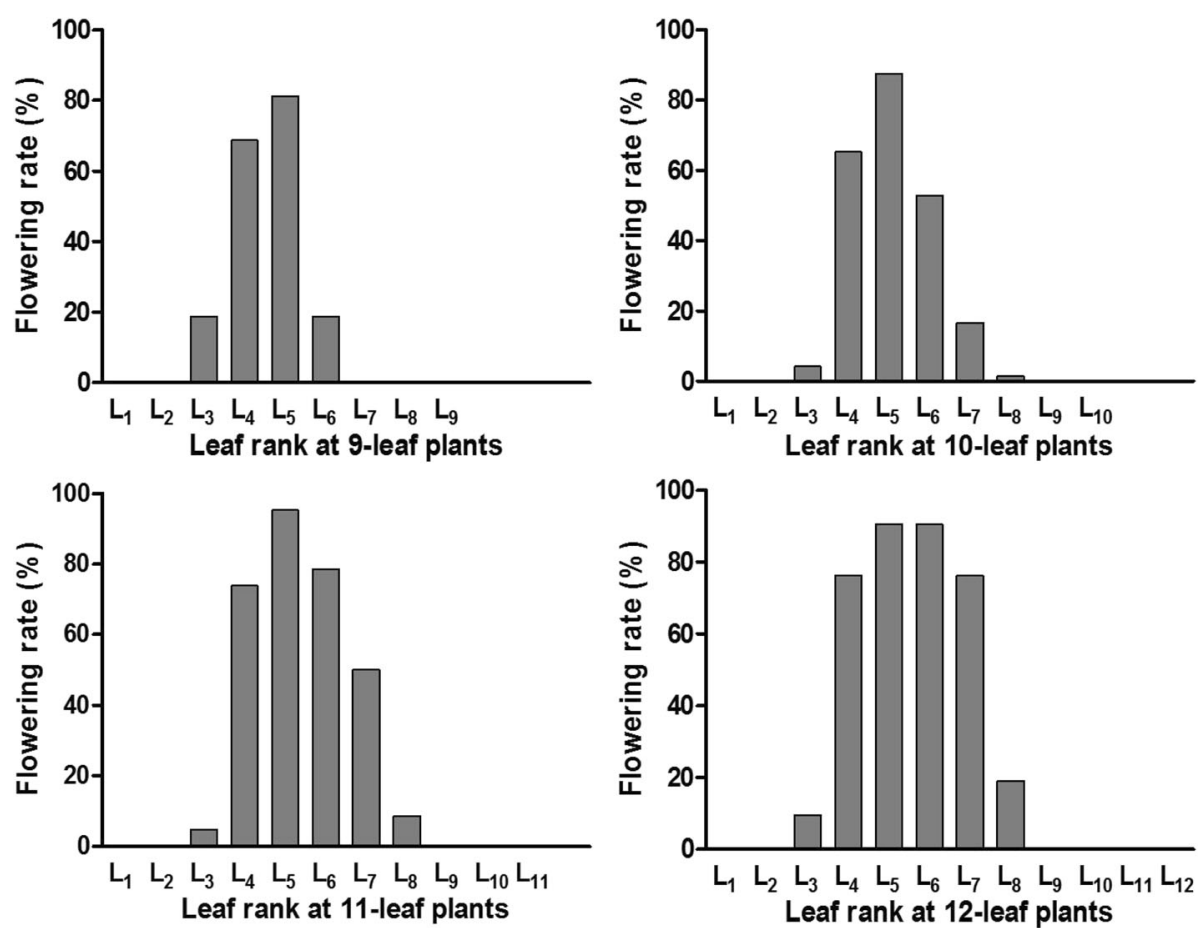

Fig. 3 Of the flowering plants (plants which had 1 or more flowers), flowering rate along the leaf rank (or node) in each number of leaves (9-L, $10-\mathrm{L}, 11-\mathrm{L}$, and 12-L) of a plant 

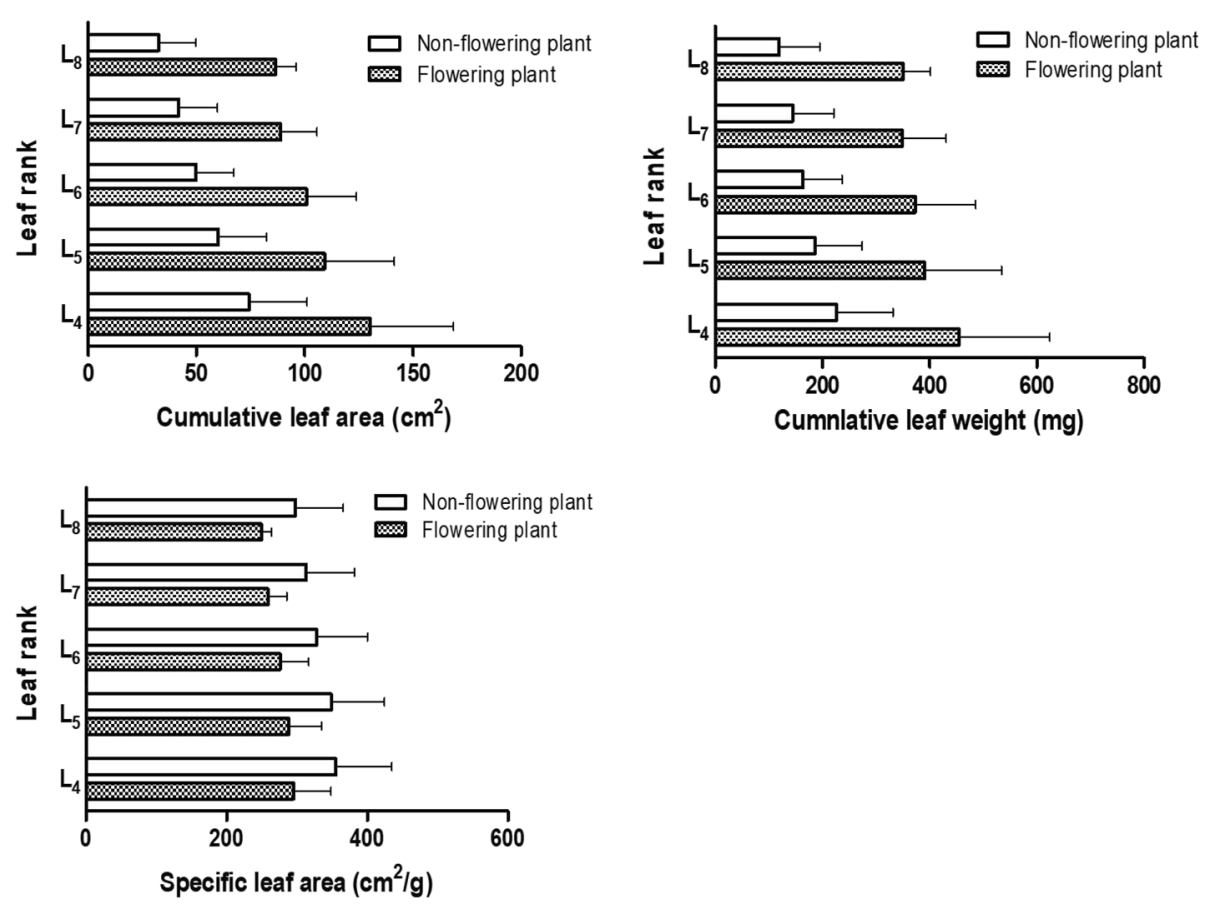

Fig. 4 Mean SLA, cumulative values of the leaf area, and the leaf dry weight in flowering and non-flowering plants. Flowering plants: plants which had a reproductive organ at each leaf rank (LR); non-flowering plants: plants which had no reproductive organ from the last leaf to the leaf rank equal to LR. LR was the closest leaf rank to the last one and had a reproductive organ

brought from the last year's rhizome, but energy for the fruit set must be transported from the nearest leaves (Stephenson 1981). Jang (2002) reported that P. humile produced 2 4 rhizomes. Production of ramets decreases the risk of genet mortality. Sexual reproduction varied negatively with both growth and vegetative propagation (Worley and Harder 1996). Shade-tolerant temperate forest herbs devote energy to sexual reproduction to a lesser extent than grassland herbs (Bierzychudek 1982). Thus, $P$. humile in a forest gap might keep at least 2 3 leaves for asexual reproduction by rhizome growth.

\section{Resource budget of new rhizome and fruit}

The dry weight of new rhizome per milligram of leaf was $0.397 \pm 0.190 \mathrm{mg}$ in plants that set fruit and
$0.500 \pm 0.263 \mathrm{mg}$ in plants that did not (Fig. 5). Difference between the 2 groups was significant at the $0.1 \%$ level, although standard deviation was large. The sum of dry weight of new rhizome and fruit per milligram of leaf was $0.520 \pm 0.177 \mathrm{mg}$ in plants that set fruit. The dry weight of new rhizome per square centimeter of leaf was $1.289 \pm 0.596 \mathrm{mg}$ in plants that set fruit and $1.689 \pm 1.003 \mathrm{mg}$ in plants that did not. The difference between the 2 groups was significant at the $0.1 \%$ level. The dry weight sum of new rhizome and fruit per square centimeter of leaf was $1.683 \pm 0.579 \mathrm{mg}$ in plants that set fruit. This value was similar to that of plants that did not set fruit. Thus, the productivity of leaves was the same in both plant groups, and sexual reproduction suppressed rhizome growth in this $P$. humile population. If
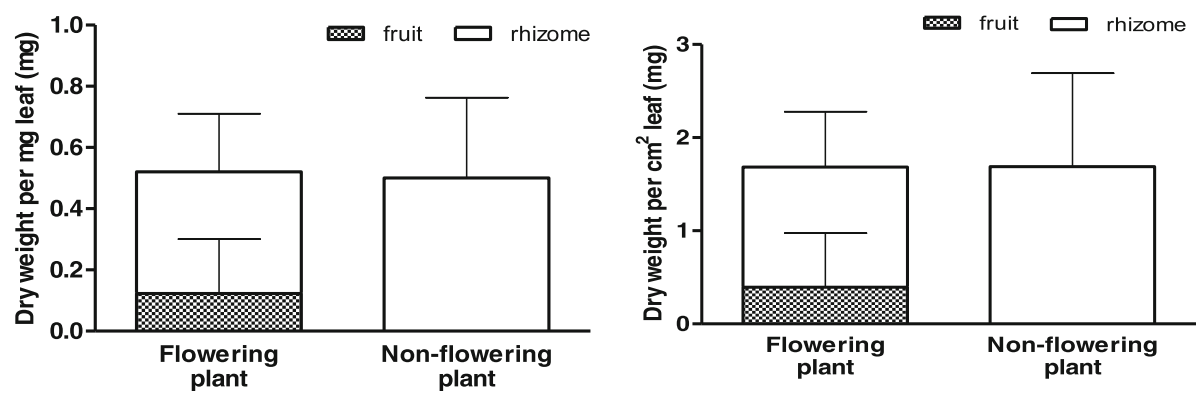

Fig. 5 Dry weight (mg) of fruit and/or new rhizome per milligram leaf dry weight (left) or per square centimeter leaf area (right) in fruit plants and non-fruit plants 
rhizome and seed reproduction are not clearly temporally separated processes, a trade-off between both reproductive modes might be expected, especially when plants grow under severe resource limitation (Stears 1989). As mentioned above, this $P$. humile population growing in a forest gap did not have sufficient sunlight and probably invested the resources in asexual rather than sexual reproduction. As a result, the fruit set was very low below $10 \%$. Generally, the proximate factor that limits fruit and seed production is the energy supply from leaf photosynthesis (Stephenson 1981). Thus, it was thought that the low fruiting rate caused more energy to be invested in the rhizomes, leading to a longer rhizome. A longer rhizome was thought to be more advantageous than a short one to avoid the shading.

\section{Conclusions}

Relationship between the sexual organ and the plant size The minimum sizes the plant needed for flowering (at least 1 flower a stem) were 9 in leaf number, $100 \mathrm{~cm}^{2}$ in total leaf area, and $200 \mathrm{mg}$ in total leaf dry weight, and the flowering rate increased with the plant sizes. Of the 3 size factors, total leaf dry weight was thought to be the most proper indicator of the relationship between the plant size and flowering.

\section{Leaf ranks (or nodes) with flower}

There was no flower at 2 nodes (to $\mathrm{L}_{2}$ ) from the bottom and at 2 4 nodes from the top in all plants. And flowering rate was highest at the $L_{5}$ in 9 12-leaf plants and decreased toward the bottom (in the direction of the $\mathrm{L}_{1}$ ) and to the top (in the direction of the last leaf). Thus, the sex organ and new rhizome might be assured of resources from the several leaves at the end and at the anterior of the stem, respectively.

\section{Resource budget of new rhizome and fruit}

Fruiting rate was $6.1 \%$ of the total flowers. And the dry weight of new rhizome per milligram of leaf was $0.397 \pm 0.190 \mathrm{mg}$ in fruiting plants and $0.500 \pm 0.263 \mathrm{mg}$ in non-fruiting plants. Thus, the low fruiting rate was thought to be a strategy for shade avoidance by allocating resources in the rhizome in a forest gap.

\section{Abbreviation}

a.s.l.: Above sea level; CC: Correlation coefficient; $L_{1}$ : The 1 st leaf on a stem (the closest leaf to soil surface); $L_{2}-L_{13}$ : The 2 nd leaf to the 13th leaf; $L_{R}$ : The leaf which was the closest to the last one and had a reproductive organ; $R_{0}$ : New (this year) rhizome; $R_{1}$ : The last year's rhizome; $R_{2}$ : Two-years-ago rhizome; $R_{3}$ : Three-years-ago rhizome; SLA: Specific leaf area

\section{Acknowledgements}

Not applicable

Funding

Not applicable
Availability of data and materials

The datasets analyzed during the current study are directly available from the fields (a natural population of Polygonatum humile), as mentioned in the "Methods" section.

Ethics approval and consent to participate

Not applicable

Consent for publication

Not applicable

Competing interests

The author declares no competing interests.

\section{Publisher's Note}

Springer Nature remains neutral with regard to jurisdictional claims in published maps and institutional affiliations.

Received: 22 February 2017 Accepted: 2 August 2017

Published online: 08 September 2017

\section{References}

Augusto, L., Dupouey, J.-L., \& Ranger, J. (2003). Effects of tree species on understory vegetation and environmental conditions in temperate forests. Annals of Forest Science, 60, 823-832.

Bierzydek, P. (1982). Life histories and demography of shade-tolerant temperate forest herbs: a review. The New Phytologist, 90, 757-776.

Choung, Y.-S. (1991). Growth characteristics and demography of Polygonatum involucratum and Polygonatum humile ramet population. J Ecol Environ, 14, 305-316.

Cook, R. E. (1983). Clonal plant population. American Scientist, 71, 244-253.

De Kroon, H., \& Schieving, F. (1991). Resource allocation patterns as a function of clonal morphology: a general model applies to a foraging clonal plant. Journal of Ecology, 79, 519-530.

Ehrlén, J., \& van Groenendael, J. (2001). Storage and the delayed costs of reproduction in the understorey perennial Lathyrus vernus. Journal of Ecology, $89,237-246$

Emborg, J. (1998). Understorey light conditions and regeneration with respect to the structural dynamics of a near-natural temperature deciduous forest in Denmark. Forest Ecology and Management, 106, 83-95.

Hartnett, D. C. (1990). Size-dependent allocation to sexual and vegetative reproduction in four clonal composites. Oecologia, 84, 254-259.

Hasegawa, T., \& Kudo, G. (2005). Comparisons of growth schedule, reproductive property and allocation pattern among three rhizomatous Polygonatum species with reference to their habitat types. Plant Species Biology, 20, 23-32.

Hirose, T., \& Kachi, N. (1982). Critical plant size for flowering in biennials with special reference to their distribution in a sand dune system. Oecologia, 55, 281-284

Houle, G. (2002). The advantage of early flowering in the spring ephemeral annual plant Floerkea proserpinacoides. The New Phytologist, 154(3), 689-694.

Jang, C.-C. (2002). A taxonomic review of Korean Polygonatum (Ruscaceae). Korean Journal of Plant Taxonomy, 32, 417-447.

Jang, K. H., Park, J. M., Kang, J. H. \& Lee, S. T. (1998). Growth and flowering characteristics of Polygonatum spp. Journal of Medicinal Crop Science, 6, 142-148.

Jerling, L. (1988). Clone dynamics, population dynamics and vegetation pattern of Glaux maritima on a Baltic sea shore meadow. Vegetatio, 74, 171-185.

Lee, T. B. (2003). Coloured flora of Korea (p. 676). Seoul: Hyangmoon Publishing Co.

Lee, W. T. (1996). Coloured standard illustrations of Korean plants (p. 399). Seoul: Academybook Co.

Legner, N., Fleck, S., \& Leuschner, C. (2013). Low light acclimation in five temperate broad-leaved tree species of different successional status: the significance of a shade canopy. Annals of Forest Science, 70, 557-570.

Klinkhamer, P. G. L., de Jong, T. M., \& Meelis, E. (1990). How to test for proportionality in the reproductive effort of plants. Amer Natl, 135, 291-300.

Klinkhamer, P. G. L., Meelis, E., de Jong, T. J., \& Weiner, J. (1992). On the analysis of size-dependent reproductive output in plant. Functional Ecology, 6, 308-316.

Reekie, E. G., \& Bazzaz, F. A. (1987). Reproductive effort in plants. 2. Does carbon reflect allocation of other resources? Am Natl, 129, 897-906. 
Samson, D. A., \& Werk, K. S. (1986). Size-dependent effects in the analysis of reproductive effort in plants. The American Naturalist, 127, 667-680.

Schemske, D. W., Willson, M. F., Melampty, M. N., Miller, L. J., Verner, L., Schemske, K. M., \& Best, L. B. (1978). Flowering ecology of some spring woodland herbs. Ecol, 59, 351-366

Schmid, B., \& Weiner, J. (1993). Plastic relationships between reproductive and vegetative mass in Solidago altissima. Evolution, 47, 61-74.

Seo, Y.-S., Park, W.-H., \& Cha, Y.-Y. (2011). Effects of Polygonatum odoratum on lowering lipid and antioxidation. J Oriental Rehab Med, 21, 49-62.

Silvertown, J. W. (1982). Introduction to population ecology (p. 209). New York: Longman Group Ltd.

Stephenson, A. G. (1981). Flowers and fruit abortion: proximate causes and ultimate functions. Ann Rev Ecol Syst, 12, 253-279.

Stears, S. C. (1989). Trade-offs in life-history evolution. Functional Ecology, 3, 259-268.

Verburg, R. W., Kwant, R., \& Werger, M. J. A. (1996). The effect of plant size on vegetative reproduction in a pseudo-annual. Vegetatio, 125, 185-192.

Worley, A. C., \& Harder, L. D. (1996). Size-dependent resource allocation and costs of reproduction in Pinguicula vulgaris (Lentibulariaceae). Journal of Ecology, 84, 195-206.

Submit your next manuscript to BioMed Central and we will help you at every step:

- We accept pre-submission inquiries

- Our selector tool helps you to find the most relevant journal

- We provide round the clock customer support

- Convenient online submission

- Thorough peer review

- Inclusion in PubMed and all major indexing services

- Maximum visibility for your research

Submit your manuscript at www.biomedcentral.com/submit
Biomed Central 